\title{
Increased frequency of in vivo hprt gene-mutated $T$ cells in the peripheral blood of patients with systemic sclerosis
}

\author{
Petros P Sfikakis, Joseph Tesar, Stamatios Theocharis, Gary L Klipple, George C Tsokos
}

\begin{abstract}
Objectives-Activated T lymphocytes are involved in the pathogenesis of scleroderma (systemic sclerosis, SSc); such cells rapidly divide in vivo and are thus theoretically subject to random mutation more frequently than resting cells. To study whether SSc is associated with rapidly expanding $T$ cell clones the frequency was determined of in vivo mutated T cells (MF) at the hypoxanthine guanine phosphoribosyl transferase (hprt) gene in the peripheral blood from patients with SSc. Specific clinical or serological associations were also investigated.

Methods-Peripheral blood lymphocytes from 16 healthy individuals and 20 patients with SSc were cultured using an hprt clonal assay; mutated and wild $T$ cell clones were established to assess individual values of $T$ cell $M F$. $T$ cell clones were further expanded in vitro and their phenotype was determined by standard immunofluorescence technique. Enzymelinked immunosorbent assays were used for simultaneous measurements of plasma levels of soluble Interleukin-2 receptors (s-IL-2R) and Intercellular adhesion molecule-1 (s-ICAM-1).
\end{abstract}

Results-Mean (SD) value of T cell MF in patients with SSc was $2 \cdot 5$-fold higher than the normal mean (SD) value $[10.6$ $(6.6) \times 10^{-6} v\left[4.4(2.8) \times 10^{-6}, p=0.0007\right]$. Eleven of 20 patients with SSc $(55 \%)$ had $T$ cell MF values greater than two SD above the normal mean value. The majority $(84 \%)$ of mutated $T$ cells had a helper/inducer, memory phenotype while $12 \%$ were cytotoxic/suppressor $T$ cells. There was no association between $T$ cell $M F$ and the extent of skin involvement or the duration of Raynaud's phenomenon. High individual $T$ cell MF values were not related to a possible concurrent immune overactivity as assessed by plasma levels of s-IL-2R and s-ICAM-1. Patients with long standing skin disease, however, had almost double $T$ cell $M F$ values than patients with early skin disease $[(13.6$ $\left.(7 \cdot 4)) \times 10^{-6} v(7.5(4 \cdot 3)) \times 10^{-6}, p=0.03\right]$, suggesting that increased $T$ cell MF in SSc may reflect an ongoing process of chronic in vivo $T$ cell proliferation and/or prolonged survival.
Conclusion-Increased in vivo $T$ cell mutation in patients with SSc suggests that excessive division and/or survival of $T$ cell clones contribute to the pathology in SSc; this approach can be used in further investigations to identify the stimulus that is triggering $T$ cell activation in this disease.

(Ann Rheum Dis 1994; 53: 122-127)

Scleroderma (systemic sclerosis, SSc) is a systemic autoimmune disorder of unknown origin. $^{12} \mathrm{~T}$ cell infiltration in early sclerodermatous lesions, ${ }^{3}$ as well as the presence of activated $T$ cells in the peripheral blood of patients with $\mathrm{SSc},{ }^{4-6}$ suggests that $\mathrm{T}$ cells may either directly (by reacting to self endothelial cells) ${ }^{7-9}$ or indirectly, (through the release of cytokines such as interleukin 2 , interleukin 4 and transforming growth factor- $\beta)^{10-12}$ play a central role in the development of vascular damage and fibrosis in patients with SSc. The hypothesis that a $\mathrm{T}$ cell-mediated autoimmune process is primarily involved in SSc is also suggested by its HLA class-II association. This hypothesis, however, remains unproven. ${ }^{1}{ }^{2}$

Cells undergoing rapid division in vivo are subject to a higher rate of spontaneous somatic mutation, presumably as a result of errors in replication, insufficient DNA repair, or fixation of the mutation. An in vivo mutation therefore occurs more frequently in activated $\mathrm{T}$ cells compared with resting $T$ cells. $T$ cells carrying mutations at the hypoxanthine guanine phosphoribosyl transferase (hprt) gene, that codes for the salvage pathway, enzyme hprt, can be clonally selected in culture by virtue of growth in the presence of 6-thioguanine which is deleterious for all cells having intact hprt gene. ${ }^{13}{ }^{14}$ By comparing the in vitro cloning efficiency of $\mathrm{T}$ cells in the absence or in the presence of 6-thioguanine, it is possible to estimate the frequency of in vivo mutated $\mathrm{T}$ cells in peripheral blood lymphocytes. ${ }^{15}{ }^{16}$ Recently, increased frequency of $h p r t$ mutant $\mathrm{T}$ cells in patients with multiple sclerosis ${ }^{17}$ and systemic lupus erythematosus (SLE) ${ }^{18}$ have been reported. Furthermore, by using the hprt clonal assay, it is possible to isolate and expand $\mathrm{T}$ cells carrying mutations that have occurred already in vivo, presumably in the presence of self-antigen(s), ${ }^{17}$ or environmental muta- 
gen(s). ${ }^{19}$ Mutant $\mathrm{T}$ cell clones from patients with multiple sclerosis demonstrated reactivity to myelin basic protein, a putative self-antigen in this disease. ${ }^{17}$

To study whether SSc is associated with rapidly expanding $T$ cell clones we determined the in vivo frequency of mutated $T$ cells in peripheral blood lymphocytes in patients with SSc, and studied the immunophenotype of mutated, as well as of non-mutated (wild), T cell clones derived from patients with SSc and normal individuals. In addition, we searched for any specific clinical associations, as well as for any possible correlation between circulating levels of immune activation markers, such as soluble Interleukin-2 receptor and Intercellular adhesion molecule- 1 , and the in vivo frequency of mutated $\mathrm{T}$ cells in the peripheral blood of these patients.

\section{Methods}

PATIENTS AND CONTROLS

Twenty patients [ 16 women, four men, mean (SD) age 42 (18) years, range 9-71 years] all of whom fulfilled the American Rheumatism Association criteria for diagnosis of definite $\mathrm{SSc}^{20}$ were studied. Fifteen of 20 patients had diffuse SSc and five patients had limited skin disease, according to the classification by LeRoy et $a l .{ }^{21}$ Disease duration was calculated from time of onset of the first clinical event, other than Raynaud's phenomenon, that was a clear manifestation of SSc. Skin involvement marked the onset of the disease in all patients. Disease duration of three years was chosen as the dividing point between early and late disease. ${ }^{22}$ All patients had Raynaud's phenomenon and its duration was also recorded. None of the patients was receiving any immunomodulatory treatment at the time of the study. Patients who had received immunomodulatory treatment other than low doses of prednisone were excluded. The protocol was approved by the Department of Clinical Investigation, Walter Reed Army Medical Center. Informed consent was obtained from all patients before venepuncture, and review of the medical records.

hprt CLONAL ASSAY

Peripheral blood mononuclear cells (PBMC) were isolated by gradient centrifugation over Ficoll-Hypaque (Sigma, St Louis, MO) of heparinised venous blood. PBMC $\left(\times 10^{6} / \mathrm{ml}\right)$ were cultured immediately in RPMI-1640 (Gibco, Grand Island, NY), supplemented with $20 \mathrm{mM}$ Hepes Buffer (Gibco), $2 \mathrm{mM}$ L-glutamine (Gibco), penicillin/streptomycin (Gibco), 5\% fetal calf serum (FCS) heat inactivated (Sigma), 20\% nutrient medium HL-1 (Ventrex, Portland, ME), in the presence of $1 \mu \mathrm{g} / \mathrm{ml}$ phytohemagglutinin (PHA, HA-16/17, Wellcome Diagnostics, Dartford, UK), for 38 hours. This priming period allows the maximum number of cells to acquire the IL-2 receptor but is not sufficient for cell division to occur. ${ }^{15}$ Subsequently the cells were suspended and counted using a haemo- cytometer. Cells were inoculated at 5, 2, 1 and 0.5 cells per well to determine cloning efficiency (CE), in $0.2 \mathrm{ml}$ of non-selection growth medium, in 96-well round bottom microtitre plates (Corning Glass Works, Corning, NY). The limiting dilution protocol was always the same. For each cell concentration, at least 144 wells were plated. Nonselection growth medium contained $65 \%$ RPMI-1640 supplemented as described above, 5\% FCS, 20\% HL-1, 10\% human T-STIM-tm without PHA, (an enriched mixture containing IL-2 and other lymphokines, Collaborative Research Inc., Bedford, MA), and $0.1 \mu \mathrm{g} / \mathrm{ml}$ PHA. In parallel, $2 \times 10^{4}$ cell per well were inoculated in selection medium (434 wells at least for each experiment) to determine the mutant frequency (MF). Selection medium was the non-selection growth medium as described above supplemented with $10^{-5} \mathrm{M}$ of 6-thioguanine (2-amino-6-mercapto-purine; Sigma). Only the cells that carry a mutation at the hprt gene are 6-thioguanine resistant. As a source of feeder cells the human lymphoblastoid cell line WIL-2 that carries a mutation at the $h p r t$ gene, designated TK6, was used. Mycoplasma-free TK6 cells (American Type Culture Collection, Rockville, MD) were irradiated with 8000 rads from a ${ }^{137} \mathrm{Cs}$ source and added $\left(15 \times 10^{3}\right.$ cells per well $)$ in all wells. In every experiment 72 wells containing growth medium and irradiated TK6 cells only served as negative control. The microcultures were incubated at $37^{\circ} \mathrm{C}$ in a humidified $5 \% \mathrm{CO}_{2}$ atmosphere for 11 days to allow colony growth.

\section{EVALUATION OF CLONING EFFICIENCY AND} MUTANT FREQUENCY OF T CELLS

The microcultures were scored for colony growth at the end of the incubation period using a phase contrast inverted microscope. Wells were classified as positive or negative for growth. All colonies that are grown under these conditions contain exclusively $T$ cells. ${ }^{13-19}$ Assuming a Poisson distribution of clonable cells in limiting dilution studies ${ }^{23}$ the cloning efficiency (CE) values for the platings of 5,2 , 1 and 0.5 cells per well were calculated as follows: $\mathrm{CE}=-\ln$ (fraction of negative wells in non-selection medium)/number of cells per well.

The mutant frequency of $\mathrm{T}$ cells $(\mathrm{MF})$ was determined as the ratio of the cloning efficiencies in selection and non-selection medium, as follows: $\mathrm{MF}=-\ln$ (fraction of negative wells in selection medium) $/ 2 \times 10^{4} /$ mean CE, where mean $\mathrm{CE}$ is the mean of the $\mathrm{CE}$ values for the platings of $5,2,1$ and 0.5 cells per well.

The CE values for the $5,2,1$, and 0.5 cell/ well platings do not represent the true cloning efficiency of $\mathrm{T}$ cells because the initial haemocytometer count does not distinguish between $T$ and $B$ cells or monocytes. However, the ratio of the cloning efficiencies in selection and nonselection medium, that is, the MF represents the true frequency of hprt mutant $\mathrm{T}$ cells because it compares $T$ cell mutants to total clonable T-cells. 
EXPANSION OF T-CELL CLONES FOR FURTHER STUDY

After scoring, $T$ cells from positive wells that had been seeded with 0.5 cell/well (wild clones) and T cells from positive wells cultured in the presence of 6-thioguanine (mutant clones) were replated in 24 well plates (Gibco) and cultured in non-selection or selection medium respectively. Irradiated TK6 cells were added at $5 \times 10^{4}$ cells $/ \mathrm{ml}$. After 3-4 days the growing clones were transferred into larger volumes and cultured in growth medium for varying periods (up to two weeks) using neither feeder cells or 6-thioguanine. At the point where each $\mathrm{T}$-cell clone reached a cell number of $3-4 \times 10^{6}$ cells, cells were harvested and used for further study. Generally, no differences were observed in the growth of clones between mutant and wild clones within each experiment.

IMMUNOFLUORESCENCE ANALYSIS OF T-CELL CLONE PHENOTYPE

One and two colour direct or indirect immunofluorescence was performed using a Becton Dickinson fluorescence-activated cell sorter (FACS) according to standard techniques. The following monoclonal antibodies were used: anti-CD-2 (T11), anti-CD3 (T3), anti-CD4 (T4), anti-CD8 (T8), anti-CD5 (T1), anti-CD19 (B4), anti-CD20 (B1), antiCD25 (IL-2R1), anti-CD45RA (2H4) and anti-CD29 (4B4) were obtained from Coulter (Hialea, FL), anti-HLA-DR was obtained from Becton Dickinson, (Mountain View, CA), anti-CD45RO (UCHL1) was obtained from Daco, (Glostrup, Denmark). In addition, the monoclonal antibodies to human $T$ cell receptor (TCR), anti- $\alpha \beta T C R$ (Identi-T PanTCR $\alpha \beta$ ) and anti- $\delta$ TCR (Identi-T TCR $\delta 1$ ) obtained from $\mathrm{T}$ Cell Sciences, (Cambridge, MA), were used.

DETERMINATION OF SOLUBLE IL-R (S-IL-2R) AND ICAM-1 (S-ICAM-1) LEVELS IN THE PLASMA OF PATIENTS

Plasma levels of s-IL-2R were measured with a sandwich enzyme linked immunosorbent assay (ELISA), using two different monoclonal antibodies against the a-chain (Tac molecule or p55) of the IL-2 receptor (T-cell Sciences). Plasma s-IL-2R values are expressed in units/ $\mathrm{ml}$ relative to a set of standards supplied with the test kit. Intra-and interassay coefficients of variation were $3.2 \%$ and $10 \%$, respectively, and recovery was $95-103 \%$.

Levels of s-ICAM-1 were measured with a sandwich ELISA method (Bender Med Systems, Vienna, Austria) using two different mouse monoclonal antibodies against the extracellular domain D4 (CL203.4) and the domain D2 (R6.5) of the ICAM-1 molecule. ${ }^{24}$ This assay is highly specific for the measurement of human s-ICAM-1 and has a minimum sensitivity of $0.625 \mathrm{ng} / \mathrm{ml}$. Intra- and interassay coefficients of variation were 3.8 and 7.8 respectively, and mean recovery was $103 \%$.
Table 1 Assessment of frequency of mutant $T$ cells in serial samples from three normal individuals using the hprt clonal assay

\begin{tabular}{lllll}
\hline Subject & \multicolumn{3}{c}{$M F^{\star}$ in sample number } & Mean (SD) \\
\cline { 2 - 4 } & 1 & 2 & 3 & \\
\hline A & $7 \cdot 9$ & $4 \cdot 2$ & $5 \cdot 8$ & $6 \cdot 0(1 \cdot 9)$ \\
B & $2 \cdot 8$ & $3 \cdot 2$ & $4 \cdot 9$ & $3 \cdot 6(1 \cdot 1)$ \\
C & $4 \cdot 3$ & $8 \cdot 5$ & $8 \cdot 8$ & $7 \cdot 2(2 \cdot 5)$ \\
\hline
\end{tabular}

${ }^{\star} \mathrm{MF}$ is expressed as number of mutants per million cells.

\section{STATISTICAL ANALYSIS}

Differences between proportions were examined using the chi-square test and differences between mean values were determined by Student's $t$ test for unpaired variables. Linear regression analysis was used to assess correlation between individual value of $M F$ and plasma s-ICAM-1 or s-IL-2R levels. Data are expressed as mean (1SD). $P$ values greater than 0.05 were considered non-significant.

\section{Results}

DETERMINATION OF $h p r t$ GENE T CELL MF IN PATIENTS WITH SSC

The in vivo $\mathrm{T}$ cell $\mathrm{MF}$ in the peripheral blood of 20 patients with SSc and 16 healthy control individuals was determined using the hprt clonal assay. We studied three normal individuals repeatedly (table 1 ). The relatively low variance of three determinations in each of the subjects studied enabled us to conclude that the used clonal assay has acceptable reproducibility. The mean (SD) MF of the control group $(n=16)$ was $[4 \cdot 4(2 \cdot 8)] \times 10^{-6}$ (range from $0,6 \times 10^{-6}$ to $10,9 \times 10^{-6}$ ). The T cell MF in the group of patients with SSc ranged from $1.9 \times 10^{-6}$ to $30.2 \times 10^{-6}$ (table 2 ), while the mean was $10.6(6.6) \times 10^{-6}$, that is, 2.5 times higher than the mean value of the control group ( $p=0 \cdot 0007)$. Eleven of 20 patients had values higher than $10 \times 10^{-6}$ which is two $S D$ above the mean value of the control group. The CE was almost similar in patients and controls $[0.42(0 \cdot 24)$ and $0.44(0 \cdot 25)$ respectively], thus the difference of $T$ cell MF between patients and controls was not due to differences in $\mathrm{CE}$ of $\mathrm{T}$ cells.

Table 2 Pertinent clinical feature, $C E$ and $T$ cell $M F$ in patients with systemic sclerosis

\begin{tabular}{|c|c|c|c|c|c|}
\hline $\begin{array}{l}\text { Patient } \\
\text { no }\end{array}$ & $\begin{array}{l}\text { Agel } \\
\text { Sex }\end{array}$ & $\begin{array}{l}\text { Years of } \\
\text { Raynaud's/ } \\
\text { skin disease }\end{array}$ & $\begin{array}{l}\text { Extent of } \\
\text { skin disease }\end{array}$ & $C E$ & $M F \ddagger$ \\
\hline 1 & $52 / \mathrm{F}$ & $12 / 11$ & D & $0 \cdot 15$ & $30 \cdot 2$ \\
\hline 2 & $48 / \mathrm{F}$ & $22 / 16$ & $\mathrm{D}$ & $0 \cdot 14$ & 19.6 \\
\hline 3 & $47 / \mathrm{F}$ & $12 / 10$ & $\mathrm{D}$ & 0.27 & $16 \cdot 1$ \\
\hline 4 & $46 / \mathrm{F}$ & $4 / 3$ & D & 0.35 & $13 \cdot 3$ \\
\hline 5 & $40 / \mathrm{F}$ & $4 / 4$ & $\bar{D}$ & $0 \cdot 31$ & $13 \cdot 1$ \\
\hline 6 & $40 / \mathrm{F}$ & $14 / 14$ & D & 0.44 & 13.0 \\
\hline 7 & $30 / F$ & $1 / 1$ & L & 0.33 & 12.5 \\
\hline 8 & $46 / F$ & $40 / 35$ & L & 0.55 & 11.8 \\
\hline 9 & $62 / \mathrm{M}$ & $6 / 5$ & L & 0.21 & $11 \cdot 3$ \\
\hline 10 & $34 / \mathrm{F}$ & $3 / 3$ & D & $0 \cdot 22$ & 10.5 \\
\hline 11 & $71 / \mathrm{F}$ & $33 / 20$ & L & 0.42 & $10 \cdot 4$ \\
\hline 12 & $9 / \mathrm{F}$ & $0.5 / 0.5$ & $\mathrm{D}$ & $0 \cdot 14$ & $9 \cdot 3$ \\
\hline 13 & $62 / \mathrm{F}$ & $30 / 2$ & L & $0 \cdot 24$ & $9 \cdot 3$ \\
\hline 14 & $52 / \mathrm{M}$ & $1 / 1$ & $\mathrm{D}$ & 0.64 & $7 \cdot 3$ \\
\hline 15 & $42 / \mathrm{M}$ & $7 / 7$ & D & 0.63 & $6 \cdot 6$ \\
\hline 16 & $36 / \mathrm{F}$ & $3 \cdot 5 / 3$ & D & 0.95 & $5 \cdot 0$ \\
\hline 17 & $34 / \mathrm{M}$ & $6 / 5$ & D & 0.75 & $3 \cdot 5$ \\
\hline 18 & $12 / \mathrm{F}$ & $2 / 2$ & $\mathrm{D}$ & 0.64 & $3 \cdot 4$ \\
\hline 19 & $13 / \mathrm{F}$ & $2 \cdot 5 / 2.5$ & D & 0.34 & $2 \cdot 9$ \\
\hline 20 & $70 / \mathrm{F}$ & $4 / 2$ & D & 0.75 & 1.9 \\
\hline
\end{tabular}

${ }^{\star}$ Diffuse (D) or limited (L) disease, $¥ M F$ is expressed as number of mutants per million cells. 
Table $3 \quad T$ cell $M F$ in various clinical subgroups of patients with systemic sclerosis

\begin{tabular}{|c|c|c|c|c|}
\hline \multicolumn{2}{|l|}{ Group (n) } & \multicolumn{2}{|c|}{$M F$, mean $/(S D)(\text { range })^{\star}$} & $p \ddagger$ \\
\hline Total SSc & (20) & $10 \cdot 6(6 \cdot 6)$ & $(1 \cdot 9-30 \cdot 2)$ & 0.0007 \\
\hline Diffuse SSc & (15) & $10 \cdot 4(7 \cdot 6)$ & $(1 \cdot 9-30 \cdot 2)$ & NSt \\
\hline Limited SSc & (5) & $11 \cdot 1(1 \cdot 2)$ & $(9 \cdot 3-12 \cdot 5)$ & \\
\hline Early SSc & (10) & $7 \cdot 5(4 \cdot 1)$ & $(1 \cdot 9-13 \cdot 3)$ & 0.03 - \\
\hline Late SSc & (10) & $13 \cdot 6(7 \cdot 4)$ & $(3 \cdot 5-30 \cdot 2)$ & \\
\hline Healthy controls & (16) & $4.4(2.8)$ & $(0 \cdot 6-10 \cdot 9)$ & \\
\hline
\end{tabular}

${ }^{\star} \mathrm{MF}$ is expressed as number of mutants per million cells. $\ddagger$ Determined by group $t$ test, §Versus healthy controls, †Versus limited SSc. IVersus Late SSc.

\section{CLINICAL ASSOCIATIONS}

The pertinent clinical features and individual $\mathrm{CE}$ and $\mathrm{T}$ cell $\mathrm{MF}$ values are presented in table 2. It is obvious that the age of the patients does not correlate with the $\mathrm{T}$ cell $\mathrm{MF}$ values. However, because three patients aged nine, 12 and 13 years had a relatively low mean $\mathrm{MF}$ value $\left(5 \cdot 2 \times 10^{-6}\right)$, we studied two normal children of the same age and sex and their $\mathrm{T}$ cell MF values were much lower $\left(0.6 \times 10^{-6}\right.$ and $3.6 \times 10^{-6}$, respectively). We then searched for possible associations between the extent of skin involvement and disease duration and MF values in patients with SSc. The range and the mean $\mathrm{T}$ cell $\mathrm{MF}$ of subgroups of patients with diffuse or limited disease, as well as with early or late disease are shown in table 3. The mean MF value in patients with diffuse truncal skin involvement was similar to that of patients with disease limited to the hands and face. Patients with duration of skin disease greater than three years had two-fold higher mean $\mathrm{T}$ cell $\mathrm{MF}$ value than patients with skin disease duration less than three years $(p=0.03)$, table 3$)$. In contrast, the duration of Raynaud's phenomenon did not correlate with $\mathrm{T}$ cell MF (table 2).

CORRELATION OF T CELL MF AND CIRCULATING MARKERS OF IMMUNE SYSTEM ACTIVATION In an attempt to assess whether concomitant immune system overactivity is associated with the presence of increased numbers of mutated $T$ cells in patients with SSc, we measured s-IL$2 \mathrm{R}$ and s-ICAM-1 in the plasma of patients that was drawn at the time of the performance of these experiments. Both s-IL-2R and s-ICAM-1 molecules have been found to be useful markers of inflammation and immune system activation in patients with SSc. ${ }^{25-29}$ Interestingly, no correlation ( $p, N S$ ) between either T cell MF values and s-IL-2R levels or s-ICAM-1 levels was found in patients with SSc (table 4), a finding that suggested that an increased $\mathrm{T}$ cell $\mathrm{MF}$ is not necessarily

Table 4 Correlation of plasma levels of s-IL2R and s-ICAM-1 with $T$ cell $M F$ values in patients with systemic sclerosis

\begin{tabular}{|c|c|c|c|c|}
\hline & \multirow[t]{2}{*}{ Mean $(S D)$} & \multicolumn{3}{|c|}{ Correlation $^{\star}$ with $M F$} \\
\hline & & (range) & $r$ & $p$ \\
\hline $\begin{array}{l}\text { s-IL2R (U/ml) } \\
\text { s-ICAM-1 (ng/ml) }\end{array}$ & $\begin{array}{l}1234(495) \\
512(144)\end{array}$ & $\begin{array}{l}(702-2286) \ddagger \\
(373-766) \S\end{array}$ & $\begin{array}{l}0.003 \\
0.117\end{array}$ & $\begin{array}{l}\text { NS } \\
\text { NS }\end{array}$ \\
\hline
\end{tabular}

accompanied by immune system overactivity at a given time during the disease. As expected, both s-IL-2R and s-ICAM-1 levels in patients with SSc were significantly higher $(\mathrm{p}<0.0001$ and $\mathrm{p}<0.001$ respectively) than normal levels.

IMMUNOPHENOTYPE OF $h p r t$ GENE-MUTATED AND WILD T CELL CLONES DERIVED FROM PATIENTS WITH SSC

A total of $86 \mathrm{~T}$ cell clones, 25 mutant and 26 wild that were derived from five patients with SSc, as well as 19 mutant and 16 mild clones that were derived from four healthy controls, were studied. All clones expressed the pan-T cell markers CD2 and CD3 on the surface membrane. In addition, all clones were $\mathrm{CD} 5^{+}$. Twenty one of $25(84 \%)$ mutant clones that were derived from the SSc patients displayed the helper $\mathrm{T}$ cell phenotype $\left(\mathrm{CD} 4^{+} \mathrm{CD} 8^{-}\right)$, whereas 3 of 25 (12\%) displayed the cytotoxic/ supressor $\mathrm{T}$ cell phenotype $\left(\mathrm{CD} 4^{-} \mathrm{CD}^{+}\right)$. One $\mathrm{T}$ cell clone was double positive $\left(\mathrm{CD}^{+}\right.$ $\mathrm{CD}^{+} \mathrm{CD}^{+}$) (table 5). It should be noted that the conditions of the clonal assay that we used to develop the above clone did not enable us to distinguish between doubly marked cells and a mixed population of singly marked cells. Similar results were obtained from the staining of the wild $\mathrm{T}$ cell clones that were derived from patients with SSc. A double negative $\left(\mathrm{CD}^{+}\right.$ $\left.\alpha \beta^{+} \mathrm{CD}^{-} \mathrm{CD}^{-}\right) \mathrm{T}$ cell clone was detected among the wild clones. The distribution of the mutant and wild $\mathrm{T}$ cell clones that were derived from healthy controls among various phenotypes did not differ (chi-square test) from the distribution of the SSc patient-derived clones (table 5). All $\mathrm{CD}^{+}$clones were activated, helper/inducer, memory $\mathrm{T}$ cells (HLADR ${ }^{+}$,

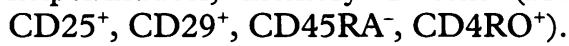

\section{Discussion}

In view of the information supporting an in vivo activation of $T$ cells in SSc patients and the fact that in vivo acquisition of any random mutation occurs preferentially in dividing cells, we assumed that the frequency of mutated $T$ cells is increased in the peripheral blood of patients with SSc. As previously reported, this assay detects mutations that have resulted from independent mutational events. ${ }^{14}$ The majority of the patients studied had increased $T$ cell $M F$, as assessed by the hprt clonal assay. Normal MF values in our hands are almost identical to normal values reported by those who developed and optimised the hprt clonal assay. ${ }^{15}$ Eleven patients of a representative

Table 5 Immunophenotype of mutant and wild T cell clones derived from healthy individuals and patients with systemic sclerosis

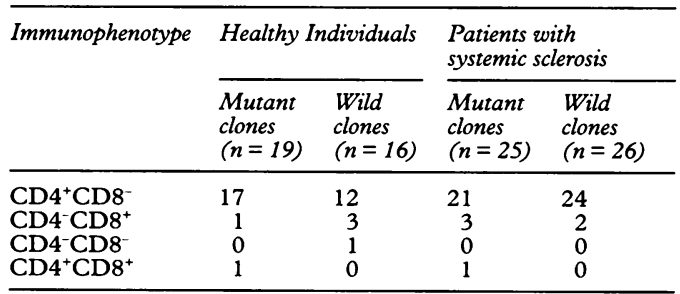


group of 20 patients with SSc had MF values higher than two SD above the normal mean value. This proportion is comparable to the proportion of patients with SLE that exhibit high $T$ cell MF (four of eight SLE patients studied, unpublished experiments). As expected, increased numbers of in vivo mutated $T$ cells is not a specific feature of SSc; theoretically, this could occur in any disease featuring chronic $T$ cell activation. This is, however, the first report of such an abnormality of $\mathrm{T}$ cells in SSc. These findings expand the evidence that $\mathrm{T}$ cells contribute to the pathology in SSc by demonstrating increased in vivo division and/or alternatively, prolonged survival.

Elevated value of $T$ cell $M F$ were not associated with the extent of skin involvement. All five patients with limited skin disease had high MF values. Duration of Raynaud's phenomenon, considered by certain investigators as the beginning of 'true' SSc disease, was also not associated with elevated $\mathrm{T}$ cell $\mathrm{MF}$ in our patients. However, 10 patients who had long standing skin disease showed significantly higher $\mathrm{T}$ cell $\mathrm{MF}$ than the 10 patients who had early ( $<3$ years) skin disease. These findings suggest that the presence of Raynaud's phenomenon before the involvement of the skin may not be associated with persistent $T$ cell activation resulting in proliferation, as with increased T cell MF, in SSc patients. Furthermore, to assess whether the increased $\mathrm{T}$ cell MF in patients with SSc was associated with concomitant overactivity of the immune system at the time of the study, we simultaneously measured circulating levels of s-IL-2R and s-ICAM-1 in the plasma of the patients studied. We elected these two soluble immunological products because s-IL-2R has been considered to be a useful marker of lymphocyte activation in general ${ }^{25}$ and in SSc in particular, ${ }^{26-28}$ and we have found that circulating s-ICAM-1 levels are elevated in patients with SSc. ${ }^{29}$ As expected, the patients in our study also had elevated plasma levels of both s-IL-2R and s-ICAM-1. No correlation was found between individual values of $\mathrm{MF}$ and either s-IL-2R or s-ICAM-1 levels. Lack of correlation indicates that $\mathrm{T}$ cell activation at a certain time of the disease does not necessarily result in increased rate of in vivo mutation, that can be detected with the $h p r t$ clonal assay. Together with the significant difference between long standing and early disease, this finding suggests that increased $T$ cell MF in patients with SSc may reflect an ongoing process of $T$ cell activation and proliferation that started in the past. Whether this process is a cause and effect in SSc or a secondary phenomenon to various other processes, such as, tissue ischaemia, cytokine effect or induction of tissue antigenicity by other processes can not be determined from this study. Serial observations starting from the beginning of the clinical symptoms in a large homogeneous group of patients will be needed to delineate the pathogenetic significance of increased $\mathrm{T}$ cell MF in SSc.

Flow cytometric analyses of $T$ cell subsets in patients with SSc have shown reduced $\mathrm{CD}^{+}$ $\mathrm{T}$ cell counts in early diffuse disease and normal $\mathrm{CD}^{+}$cell counts in patients with late disease. ${ }^{622}$ Normal $^{22}$ or increased ${ }^{30}$ numbers of helper/inducer $\left(\mathrm{CD}^{+} \mathrm{Cd} 29^{+}\right) \mathrm{T}$ cells, and increased ${ }^{22}$ or normal $^{30} \mathrm{CD}^{+}$to $\mathrm{CD}^{+}$ratio have also been reported in the peripheral blood of patients with SSc. Most recently it was reported that patients with SSc have increased numbers of double negative $\left(\mathrm{CD} 4^{-} \mathrm{CD} 8^{-}\right)$ peripheral blood $\mathrm{T}$ cells that displayed a rather restricted $T$ cell receptor $V \beta$ repertoire. ${ }^{31}$ To our knowledge, $\mathrm{T}$ cell clones from scleroderma patients have not been established previously. We describe the phenotype of such $T$ cell clones derived from peripheral blood lymphocytes. The majority $(91 \%)$ of the wild $\mathrm{T}$ cell clones, as well as $84 \%$ of the $h p r t$ genemutated $\mathrm{T}$ cell clones that we established from SSc patients were helper $\mathrm{T}$ cells. No differences were observed in the distribution of $T$ cell clone phenotype between patients and normal individuals. The apparent preponderance of $\mathrm{CD}^{+} \mathrm{T}$ cell clones may be due to the fact that $\mathrm{CD}^{+}$cells can be cloned easier than $\mathrm{CD}^{+}$cells. In fact, suppressor $\mathrm{T}$ cells from the peripheral blood have been cloned in only a few instances, ${ }^{32}$ and although unclear, the majority of self-reactive $\mathrm{T}$ cells that have been characterised to date are confined to the subpopulation of helper $\mathrm{T}$ cells. ${ }^{33}$ Because of the relatively small number of $T$ cell clones that we established from patients with SSc we did not come across any double negative ones. Identification and expansion of such clones may contribute to our understanding of the disease. ${ }^{31}$ All the hprt gene-mutated $\mathrm{T}$ cell clones that were established from both patients with SSc and normal individuals were activated, memory, lymphocytes (HLADR ${ }^{+}$ $\mathrm{CD}_{25}{ }^{+} \mathrm{CD} 45 \mathrm{RA}^{-} \mathrm{CD} 45 \mathrm{RO}^{+}$). Memory $\mathrm{T}$ lymphocytes is the result of the clonal expansion of antigen-reactive cells, are long lived, and selectively traffic from the blood to peripheral tissue. ${ }^{34}$ However, some of these clones may not have been derived from in vivo activated memory $T$ cells, because the clones are IL-2 dependent in vitro and it is known that during prolonged culture periods immature $\left(\mathrm{CD} 45 \mathrm{RA}^{+}\right) \mathrm{T}$ cells may express the $\mathrm{CD} 45 \mathrm{RO}^{+}$antigen on their surface. ${ }^{35}$

One of the potential mechanisms whereby $T$ cells become activated in vivo in SSc may involve a reaction to autoantigenic epitopes. ${ }^{1}$ The study of self-reactive $T$ cells in SSc has been hampered by their rarity in the accessible tissues and the difficulty of obtaining them in vitro without antigenic stimulation. Clones that are derived after in vitro antigenic stimulation are of questionable pathophysiological importance because they can also be obtained from normal individuals and they may derive from cells that are otherwise tolerant. ${ }^{33}$ The hprt clonal assay presents an opportunity to select in vitro $T$ cells that have been activated in vivo, including those that have encountered non-tolerogenic autoantigens. Further experiments to confirm the pathogenic relevance of $\mathrm{T}$ cell clones derived using the hprt clonal assay in SSc are currently underway. $\mathrm{T}$ cells that are more likely to sustain this somatic mutation, such as the 
rapidly proliferating in vivo $\mathrm{T}$ cells, may be able to preferentially focus on the skin and other involved organs and initiate or perpetuate the pathogenic process that leads to fibrosis.

In conclusion, the frequency of in vivo mutated $\mathrm{T}$ cells in the peripheral blood of patients with SSc is increased, suggesting excessive division and/or survival of circulating $\mathrm{T}$ cells. Chronic (self)-antigenic stimulation may account for this finding. Selection of mutated $\mathrm{T}$ cells from peripheral blood of these patients may therefore be used to identify the stimulus that is triggering $T$ cell activation in this disease. Such studies will improve our understanding of the pathogenesis of SSc and may direct our therapeutic efforts towards the elimination of selected pathogenic $\mathrm{T}$ cell subpopulations. ${ }^{36}$

We thank Dr P Panayiotides for helpful discussions and for critical reading of the manuscript and Drs D Monos and B
Cizman for their advice and help during the initial phases of the experiments. We are grateful to Mr L Billops for performing the FACS analysis and Mrs L Teale for testing the TK6 cells for mycoplasma. Dr Sfikakis is a recipient of a scholarship from the A Onassis Foundation.

1 LeRoy E C. A brief overview of the pathogenesis of scleroderma (systemic sclerosis). Ann Rheum Dis 1992; 51: $286-8$.

2 Postlethwaite A E. Early immune events in scleroderma Rheum Dis Clin North Am 1990; 16: 125-9.

3 Roumm SD, Whiteside T L, Medsger T A, Rodnan G P. Lymphocytes in the skin of patients with progressive systemic sclerosis: quantification, subtyping and clinical correlations. Arthritis Rheum 1984; 27: 645-53.

4 Freundlich B, Jimenez S A. Phenotype of peripheral blood lymphocytes in patients with progressive systemic
sclerosis: activated $T$ lymphocytes and the effect of sclerosis: activated T lymphocytes and the effect of D-penic

5 Kahan A, Gerfaux J, Joret A M, Menkes C, Amor B Increased proto-oncogene expression in peripheral blood $\mathrm{T}$ lymphocytes from patients with systemic sclerosis. Arthritis Rheum 1989; 32: 430-36.

6 Gustafsson R, Totterman T H, Klareskog L, Hallgren R. Increase in activated $T$ cells and reduction in suppressor inducer T cells in systemic sclerosis. Ann Rheum Dis 1990; inducer $T$. $40-5$.

7 Hawrylko E, Spertus A, Mele C A, Oster N, Frieri M Increased interleukin-2 production in response to human type I collagen stimulation in patients with systemic sclerosis. Arthritis Rheum 1991; 34: 580-7.

8 Huffstutter J E, DeLustro F A, Leroy E C. Cellular immunity to collagen and laminin in scleroderma. Arthritis Rheum 1985; 28: 775-80.

9 Maul G G, Jimenez S A, Riggs E, Ziemnicka-Kotula D. Determination of an epitope of the diffuse systemic sclerosis marker antigen DNA topoisomerase I: Sequence similarity with retroviral p30gag protein suggests a possible similarity with retroviral p30 $30^{\text {gag }}$ protein suggests a possible Acad Sci 1989; 86: 8492-6.

10 Kahaleh M B, Leroy E C. Interleukin-2 in scleroderma correlation of serum level with extent of skin involvemen and disease duration. Ann Intern Med 1989; 110: 446-50.

11 Postlethwaite A E, Holness M A, Katai H, Raghow R Human fibroblasts synthesize elevated levels of extracellular matrix proteins in response to interleukin 4. f Clin Invest 1992; 90: 1479-85.

12 Sfikakis $P$ P, McCune $B$ K, Tsokos M, Aroni $K$, Vayiopoulos G, Tsokos G C. Immunohistological demonstration of transforming growth factor-b isoform expression in the skin of patients with Systemic Sclerosis. Clin Immunol Immunop 1993; 69: 199-204.
13 Albertini R J, O'Neil J P, Nicklas J A, Heintz N, Kelleher $P$ C. Alterations of the hprt gene in human in vivo-derived 6-thioguanine resistant T lymphocytes. Nature 1985; 316: 6-thioguani

14 Nicklas J A, O’Neill J P, Albertini R J. Use of T cell receptor gene probes to quantify the in vivo hprt mutations in human T lymphocytes. Mutation Res 1986; 173: 67-72.

15 O'Neill J P, McGinniss M J, Berman J K, Sullivan L M, Nicklas J A, Albertini R J. Refinement of a T-lymphocyte cloning assay to quantify the in vivo thioguanine-resistant mutant frequency in humans. Mutagenesis 1987; 2: mutant

16 Henderson L, Cole $\mathrm{H}$, Cole J, James S E, Green $\mathrm{M}$. Detection of somatic mutations in man: evaluation of the microtiter cloning assay for T-lymphocytes. Mutagenesis 1986; 1: 195-200.

17 Allegretta M, Nicklas J A, Sriram S, Alvertini R J. T cells responsive to myelin basic protein in patients with multiple sclerosis. Science 1990; 247: 718-21.

18 Gmelig-Meylig F, Dawisha F S, Steinberg A D. Assessment of in vivo frequency of mutated $T$ cells in patients with systemic lupus erythematosus. F Exp Med 1992; 175: 297-300.

19 Messing K, Bradley W E C. In vivo mutant frequency rises among breast cancer patients after exposure to high doses of irradiation. Mutation Res 1985; 152: 107-12.

20 Subcommittee for Scleroderma Criteria of the American Rheumatism Association Diagnostic and Therapeutic Criteria Committee: Preliminary criteria for the classification of systemic sclerosis (scleroderma). Arthritis Rheum 1980; 23: 581-90.

21 LeRoy E C, Black C, Fleishmajer R, et al. Scleroderma (systemic sclerosis): classification, subsets and pathogenesis. 7 Rheumatol 1988; 15: 202-5.

22 Kantor T V, Whiteside T I Friberg D, Buckingham R B Medsger T A. Lymphokine-activated killer cell and natural killer cell activities in patients with systemic natural killer cell activities in patients
sclerosis. Arthritis Rheum 1992; 35: 694-9.

23 Taswell C. Limiting dilution assays for the determination of immunocompetent cell frequencies. $\mathcal{F}$ Immunol 1981 ; 126: 1614-19.

24 Standton D G, Dustin M L, Erickson H P, Springer T A. The arrangement of the immunoglobulin-like domains of ICAM-1 and the binding sites for LFA-1 and rhinovirus. Cell 1990; 61: 243-4.

25 Rubin LA, Nelson D L. The soluble Interleukin-2 receptor: Biology, function, and clinical application. Ann Intern Med 1990; 113: 619-27.

26 Korn J H. Immunologic aspects of scleroderma. Cur Opin Rheumatol 1991; 3: 947-52.

27 Kahaleh B. Soluble immunologic products in Scleroderma sera. Clin Immunol Immunpathol 1991; 58: 139-44.

28 Degiannis D, Seibold J R, Czarnecki M, Roskova J, Raska $\mathrm{K}$. Soluble interleukin-2 receptors in patients with Systemic sclerosis. Clinical and laboratory correlations. Arthritis Rheum 1990; 33: 375-80.

29 Sfikakis P P, Tesar J, Baraf H, Lipnick R, Klipple G I Tsokos G C. Circulating intercellular adhesion molecule 1 in patients with Systemic Sclerosis. Clin Immunol Immunopathol 1993; 68: 88-92

30 Kahan A, Kahan A, Picard F, Menkes C J, Amor B. Abnormalities of $T$ lymphocyte subsets in systemic sclerosis demonstrated with anti-CD45RA and antiCD29 monoclonal antibodies. Ann Rheum Dis 1991; 50: 354-8.

31 Sakamoto A, Sumida T, Maeda $T$, et al. $T$ cell receptor $V \beta$ repertoire of double-negative $a / \beta T$ cells in patients with systemic sclerosis. Arthritis Rheum 1992; 35: 944-8.

32 Sercarz E, Krzych U. The distinctive specificity of antigenspecific suppressor T cells. Immunol Today 1991; 12: 111-8.

33 Finnegan A, Needleman B W, Hodes R J. Function of autoreactive $\mathrm{T}$ cells in immune responses. Immunol Rev 1990; 116: 15-31.

34 Mackay C R, Marston W L, Dudler L. Naive and memory $\mathrm{T}$ cells show distinct pathways of lymphocyte recirculation. f Exp Med 1990; 171: 801-7.

35 Ferrer J M, Pleza A, Kreisler M, Diaz-Espada F. Differential interleukin secretion by in vitro activated human $\mathrm{CD}^{2} 5 \mathrm{RA}^{+}$and $\mathrm{CD} 45 \mathrm{RO}^{+} \mathrm{CD} 4^{+} \mathrm{T}$ cell subsets. Cell Immunol 1992; 141: 336-9.

36 Wraith D C, McDevitt H O, Steinman L, Acha-Orbea H. $T$ cell recognition as the target for immune intervention in autoimmune disease. Cell 1989; 57: 709-15. 